\title{
Obtención de sílice precipitada en un sistema de dos reactores consecutivos
}

\author{
Diego Zapater, Ramón Campo, Jaime Soler, Miguel Menéndez \\ Catalysis, Molecular Separations and Reactor Engineering Group (CREG). \\ Instituto de Investigación en Ingeniería de Aragón (I3A) \\ Universidad de Zaragoza, Mariano Esquillor s/n, 50018, Zaragoza, Spain. \\ Tel.+34-976762707, e-mail:_diegozbes@gmail.com
}

\begin{abstract}
La sílice precipitada es un producto que se ha obtenido tradicionalmente en un reactor discontinuo. Se propone la modificación del este sistema mediante la implementación de dos reactores consecutivos cuyo carácter más versátil hace posible la modificación de un mayor número de variables de precipitación para definir el producto final.
\end{abstract}

\section{Introducción}

La sílice precipitada es un producto ampliamente utilizado en diferentes industrias como neumáticos, piezas de caucho, farmacia o alimentación animal debido a sus características de porosidad y adsorción [1].

En este trabajo se pretende modificar el proceso tradicional de producción de sílice precipitada implementando un sistema de dos reactores consecutivos. Mediante éste se estudia el efecto de las variables de precipitación, con el objetivo de obtener un producto cuya estructura presente alta porosidad y capacidad de adsorción [2].

La reacción de formación de sílice precipitada por vía húmeda parte de la mezcla de silicato de sodio y ácido sulfúrico (Reacción 1). Durante ésta se produce la formación del ácido silícico y su polimerización para formar partículas primarias [3].

$r \cdot \mathrm{SiO}_{2} \cdot \mathrm{Na}_{2} \mathrm{O}+\mathrm{H}_{2} \mathrm{SO}_{4} \rightarrow r \cdot \mathrm{SiO}_{2}+\mathrm{Na}_{2} \mathrm{SO}_{4}+\mathrm{H}_{2} \mathrm{O}$ (R.1)

Las partículas formadas evolucionan hacia diferentes productos en función de las condiciones de operación. A bajas concentraciones de sílice y sodio en el medio ( $20 \mathrm{~g} \mathrm{SiO2/L} \mathrm{y}<0,2 \mathrm{~mol}$ $\left.\mathrm{Na}^{+} / \mathrm{L}\right)$ y $\mathrm{pH}>7$ se produce el crecimiento de las partículas en forma de un sol de sílice. Cuando estas concentraciones aumentan hasta un valor crítico, se produce la agregación en grupos de partículas que precipitan [4]. Esta agregación sucede por gelificación si se trabaja a $\mathrm{pH}<7$ o por floculación si se trabaja a $\mathrm{pH}=7-10$, actuando en esta última el ion sodio como agente floculante.

\section{Experimental}

Como reactivos se utiliza silicato de sodio $\left(3,39 \cdot \mathrm{SiO}_{2} \cdot \mathrm{Na}_{2} \mathrm{O}\right)$ de concentración 40, 60 y 160 g/L y ácido sulfúrico $\left(\mathrm{H}_{2} \mathrm{SO}_{4}\right)$ de concentración 19, 38 y 76 g/L. Estos se adicionan al primer reactor (de $3 \mathrm{~L}$ de capacidad) en el que se genera el sol de sílice durante $18 \mathrm{~min}$. Tras esto, el sol que se va formando se adiciona sobre el segundo reactor (de $9 \mathrm{~L}$ de capacidad) durante $120 \mathrm{~min}$, en los cuales se produce el crecimiento y la evolución de la sílice precipitada. Posteriormente se detiene la adición del sol de sílice y se adiciona silicato de sodio (160 g/L) y ácido sulfúrico $(76 \mathrm{~g} / \mathrm{L})$ para enriquecer el medio en sílice.

El producto final obtenido se caracteriza mediante isotermas de adsorción de $\mathrm{N}_{2}$ (área BET y tamaño de partícula), porosimetría de mercurio (tamaño y volumen de poros) y adsorción de dioctil adipato (capacidad de adsorción).

\section{Resultados y discusión}

Se ha estudiado el efecto que tiene, sobre el producto final, la concentración de sílice adicionada al primer reactor, la concentración inicial de $\mathrm{Na}^{+}$en el segundo reactor, el $\mathrm{pH}$ en la formación del sol, el $\mathrm{pH}$ en el segundo reactor y el tiempo de crecimiento del sol. La caracterización de los productos se presenta en la Tabla 1. Estos se muestran a través de las imágenes TEM en la Figura 1.

Efecto de la concentración de $\mathrm{SiO}_{2}$

$\mathrm{Al}$ trabajar con mayor concentración $\left(60 \mathrm{~g} \mathrm{SiO}_{2} / \mathrm{L}\right)$, en el primer reactor se produce la gelificación, por lo cual al segundo reactor se adiciona un gel, en lugar de un sol de sílice. Como resultado, las partículas obtenidas poseen gran distribución de 
tamaños de partícula (Figura 1-A) y al agregarse forman una estructura con menor volumen de poro y menor capacidad de adsorción, comparada con la obtenida al trabajar con menor concentración (Figura 1-B).

\section{Efecto de la concentración inicial de $\mathrm{Na}^{+}$}

Al partir de un lecho inicial con carga iónica en el segundo reactor $\left(0,4 \mathrm{~mol} \mathrm{N^{+ } / L )}\right.$ se favorece la agregación de las partículas frente al crecimiento (Figura 1-C), obteniéndose partículas generalmente menores que con $0 \mathrm{~mol} \mathrm{Na}+\mathrm{L}$ (Figura 1-D). La estructura porosa que se forma, como resultado de la agregación, presenta menor volumen de poros y menor capacidad de adsorción.

\section{Efecto del pH en la formación del sol}

El pH en el primer reactor no afecta a la formación de las partículas del sol de sílice en el rango estudiado, $\mathrm{pH}=8$ (Figura 1-E) y $\mathrm{pH}=9$ (Figura 1A). Estas partículas, que poseen tamaños similares en ambos casos, se agregan en el segundo reactor obteniéndose una estructura porosa final con volumen de poros y capacidad de adsorción similar.

\section{Efecto del pH en el segundo reactor}

En el segundo reactor el $\mathrm{pH}$ tiene efecto sobre la precipitación. Al trabajar a $\mathrm{pH}=7$ (Figura 1-D) el medio de reacción es menos estable respecto a la agregación que cuando se trabaja a $\mathrm{pH}=8$ (Figura 1C). Ésta disminución en la estabilidad del sistema hace que se produzcan más interacciones entre las partículas de sílice y que por tanto se favorezca su agregación, obteniéndose partículas de menor tamaño y formándose una estructura porosa que presenta mayor volumen de poros y capacidad de adsorción.

\section{Efecto del tiempo de crecimiento del sol}

Se estudia el efecto del tiempo de crecimiento del sol, para 0 y 30 min, de forma independiente para dos concentraciones iónicas ( 0 y $\left.0,4 \mathrm{~mol} \mathrm{Na}^{+} / \mathrm{l}\right)$ en el segundo reactor, ya que se conoce que ésta afecta al proceso de precipitación [5].

Cuando se trabaja sin carga iónica inicial en el segundo reactor un mayor tiempo de crecimiento del sol proporciona mayor distribución de tamaños de partícula (Figura 1-F), que al agregarse forman una estructura de menor volumen de poros y menor adsorción que cuando no se tiene este crecimiento adicional (Figura 1-C).

Cuando se tiene carga iónica inicial, mayores tiempos de crecimiento resultan en partículas y estructura porosa similares pero que proporciona menor adsorción.

\section{Conclusiones}

Se ha adaptado un sistema de precipitación tradicional a un sistema novedoso de producción mediante dos reactores. El sistema actual presenta una mayor versatilidad, lo que permite definir las características finales del producto en función de las variables de proceso.

Como resultado del estudio de variables se ha obtenido que la concentración de sílice adicionada al primer reactor, la presencia de carga iónica inicial en el segundo reactor, el $\mathrm{pH}$ en éste y el tiempo de crecimiento del sol afectan de forma directa a la estructura porosa que se obtiene, su aumento disminuye el volumen de poros y la capacidad de adsorción que presenta la sílice. A su vez, se ha obtenido que el pH no afecta a la formación del sol de sílice en el primer reactor en el rango estudiado.

\section{REFERENCIAS}

[1]. JULVE, D.J. Estudio de sílices precipitadas para la mejora de mezclas de caucho. Departamento de ingeniería química y tecnologías del medio ambiente, Universidad de Zaragoza, 2009. Tesis doctoral.

[2]. CHEVALLIER, Y., and CHIMIE, R. Silica with a high oil absorption capability and a controlled primary structure and process for the production thereof. U.S. Patent No 4708859. 1987.

[3]. ILER, R.K. The Chemistry of Silica: Solubility, Polimerization, Colloid and Surface Properties, and Biochemistry. Jhon Wiley \& Sons, New York. 1979.

[4]. SCHLOMACH, J., and KIND, M. Investigations on the semi-batch precipitation of silica, Journal of Colloid Interface Science.. 2004, 277 (2), 316-326.

[5]. SCHAER, E., RAVETTI, R., and PLASARI, E. Study of silica particle aggregation in a batch agitated vessel.Cemical Engineering Process. 2001, 40 (3), 277-293. 
Tabla 1. Caracterización de la sílice precipitada obtenida como producto final.

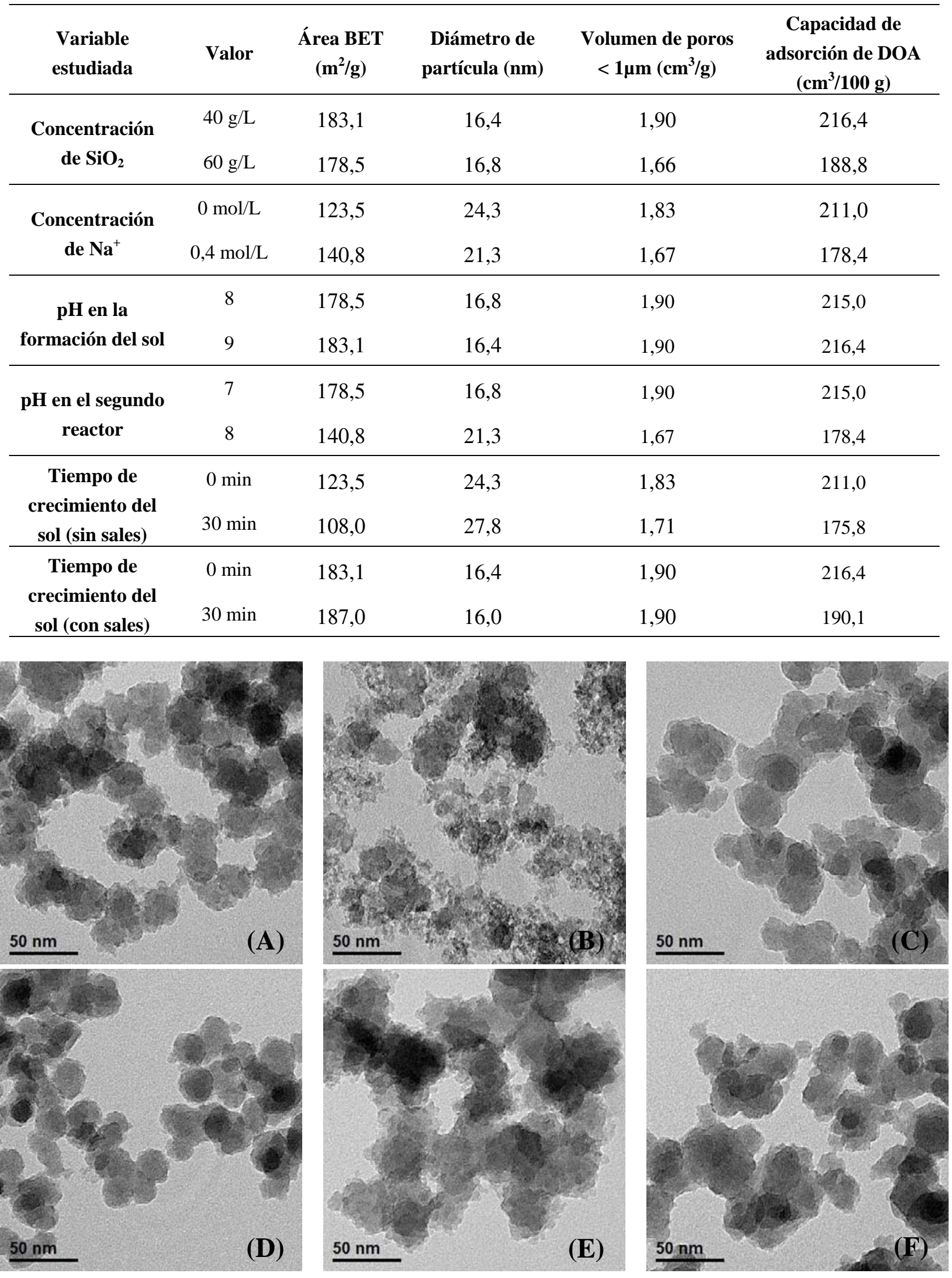

Figura 1. Imágenes TEM obtenidas para el producto final de precipitación.

Revista "Jornada de Jóvenes Investigadores del I3A", vol. 5 (Actas de la VI Jornada de Jóvenes Investigadores del I3A - 2 de junio de 2017). ISSN 2341-4790. 